\title{
Plasma bilirubin level and oxidative stress in preterm infants
}

\author{
C Dani, E Martelli, G Bertini, M Pezzati, L Filippi, M Rossetti, G Rizzuti, F F Rubaltelli
}

Arch Dis Child Fetal Neonatal Ed 2003;88:F119-F123

See end of article for authors' affiliations

.....................

Correspondence to: Dr Dani, Division of Neonatology, Careggi University Hospital, University of Florence School of Medicine, Viale Morgagni, 85 Firenze, Italy; cdani@cesit1.unifi.it

Accepted 4 June 2002

\begin{abstract}
Objective: To assess the hypothesis that changes in plasma total bilirubin levels (Btot) can influence the antioxidant system and oxidative stress in preterm infants.

Methods: Twenty two healthy preterm infants who presented with visible non-haemolytic hyperbilirubinaemia were studied at the mean (SD) age of 3.7 (1.5) days. Btot, plasma total hydroperoxide concentration $(\mathrm{TH})$, plasma protein SH group concentration, and total antioxidant capacity of the plasma (TAC) were measured at study entry and after 24 hours.

Results: Btot did not correlate with TH, TAC, or protein SH group concentration, but a significant correlation was found between TH and TAC, TH and protein SH groups, and TAC and protein SH groups, both at study entry and after 24 hours.

Conclusion: The decrease in plasma bilirubin was contemporary with an increase in plasma antioxidant capacity and decrease in oxidative stress in preterm infants. This may be the result of the pro-oxidant effect of haem oxygenase, mediated by iron release, which may outcompete the antioxidant properties of bilirubin.
\end{abstract}

M any illnesses in preterm infants, such as chronic lung disease, necrotising enterocolitis, retinopathy of prematurity, and intracranial haemorrhage, are thought to be related to the action of reactive oxygen species. They occur because the antioxidant system of preterm infants is highly stressed and incompletely developed. ${ }^{1}$ Several reports have emphasised the antioxidant role of bilirubin, which in human neonatal plasma seems to have a greater antioxidant capacity than urates, $\alpha$-tocopherol, or ascorbates. ${ }^{2}$ Bilirubin reactions involving free radicals or toxic products of oxygen reduction have been well documented. In particular, unconjugated bilirubin is able to scavenge singlet oxygen with high efficiency, to react with superoxide anions and peroxyl radicals, and to serve as a reducing substrate for peroxidases in the presence of hydrogen peroxide or organic hydroperoxides. ${ }^{3}{ }^{4}$ However, although the antioxidant effect of bilirubin as a scavenger of reactive oxygen species is well documented in vitro ${ }^{5-8}$ and animal studies, ${ }^{9}$ its role in vivo has not been clarified in preterm infants. ${ }^{10-13}$ Yigit et a $l^{10}$ reported that serum malondialdehyde concentrations were higher in infants with hyperbilirubinaemia than in controls, and other authors $^{11-13}$ have found a significant correlation between serum bilirubin and total antioxidant capacity of the plasma.

The hypothesis of our study was that changes in plasma bilirubin levels may influence the antioxidant system and oxidative stress in newborn infants. Therefore, our aim was to investigate the possible correlation between plasma bilirubin level and oxidative stress and the antioxidant capacity of plasma in preterm infants. To this end, we planned a prospective study in which the plasma levels of total bilirubin (Btot), total hydroperoxide ( $\mathrm{TH}$ ), and protein $\mathrm{SH}$ groups, and the total antioxidant capacity of plasma (TAC) were concurrently measured.

\section{METHODS}

The study was conducted in the neonatal intensive care unit of the University Hospital of Florence after approval by the local ethics committee.

After obtaining parental consent, we studied 22 healthy preterm infants $\leqslant 7$ days of age who were consecutively enrolled in the study if they were $\leqslant 36$ weeks of gestational age, showed visible signs of non-haemolytic hyperbilirubinaemia, did not require respiratory support, were clinically stable, did not suffer perinatal asphyxia or sepsis, and had no major congenital malformations.

For each newborn infant, sex, gestational age, birth weight, type of delivery, Apgar score at five minutes, antenatal steroid treatment, main pathologies, and pregnancy diseases were recorded. Btot was measured at study entry and then again after 24 hours by reflectance spectrophotometry (Microbilimeter, Ginevri, Rome, Italy). The accuracy of Btot measurement in our unit was recently tested, and the correlation between our laboratory method and the HPLC method was high $(r=0.927 ; 95 \%$ confidence interval $=0.906$ to 0.944$) .{ }^{14}$

At the same times, a heparinised blood sample was obtained to measure plasma concentrations of albumin, ferritin, total iron, TH, and protein SH groups, and TAC. The blood samples were often obtained from the umbilical vein catheter to reduce the number of painful interventions. Infusion contamination was prevented by aspirating the infused solution and at least $0.5 \mathrm{ml}$ blood from the catheter before collection of blood for analysis.

To more precisely interpret the changes in TH, TAC, and protein $\mathrm{SH}$ groups in preterm infants, we also studied nine infants without visible hyperbilirubinaemia. The infants had clinical characteristics similar to those of the study group.

Conventional phototherapy (Photo-Therapie 800; Drager, Lübeck, Germany) was started when Btot was $>220 \mu \mathrm{mol} / \mathrm{l}$, and was discontinued when the level was $\leqslant 170 \mu \mathrm{mol} / \mathrm{l}$.

\section{Procedures}

The blood samples were immediately centrifuged, and all analyses of TH, TAC, and protein $\mathrm{SH}$ groups were carried out within two hours of blood sampling to avoid the effects of storage. TH is a measure of overall oxidative stress, given that

Abbreviations: Btot, plasma total bilirubin concentration; TAC, total antioxidant capacity of the plasma; TH, plasma total hydroperoxide concentration 
Table 1 Comparison of Btot, TH, TAC, and SH groups in plasma of infants with and without visible jaundice

\begin{tabular}{|c|c|c|c|}
\hline & $\begin{array}{l}\text { Infants with jaundice } \\
(n=22)\end{array}$ & $\begin{array}{l}\text { Infants without jaundice } \\
(n=9)\end{array}$ & $\mathrm{p}$ Value \\
\hline Male/female & $12 / 10$ & $4 / 5$ & $>0.05$ \\
\hline Gestational age (weeks) & $31.9(3.9)$ & $31.6(1.8)$ & $>0.05$ \\
\hline Birth weight $(g)$ & 1550 (330) & 1490 (280) & $>0.05$ \\
\hline Caesarean section & $15(68 \%)$ & $6(67 \%)$ & $>0.05$ \\
\hline Apgar score (5 min) & $7.5(2.1)$ & $7.1(2.3)$ & $>0.05$ \\
\hline Antenatal steroids & $18(82 \%)$ & $7(78 \%)$ & $>0.05$ \\
\hline \multicolumn{4}{|l|}{ Pregnancy diseases } \\
\hline Gestosis & $13(59 \%)$ & $5(56 \%)$ & $>0.05$ \\
\hline PROM & $3(14 \%)$ & $1(11 \%)$ & $>0.05$ \\
\hline Preterm labour & $6(27 \%)$ & $3(33 \%)$ & $>0.05$ \\
\hline \multicolumn{4}{|l|}{ Age at: } \\
\hline 1st blood sample & $3.7(1.5)$ & $3.9(1.2)$ & $>0.05$ \\
\hline 2nd blood sample & $4.6(1.6)$ & $4.9(1.3)$ & $>0.05$ \\
\hline \multicolumn{4}{|l|}{ Btot $(\mu \mathrm{mol} / \mathrm{l})$} \\
\hline At study entry & $219.0(25.9)$ & $94.8(8.6)$ & $<0.05$ \\
\hline After 24 hours & $188(27.6)$ & $105(17.7)$ & $<0.05$ \\
\hline \multicolumn{4}{|l|}{ TH (Carr units/ml) } \\
\hline At study entry & 151.8 (39.7) & $101.3(27.8)$ & $<0.01$ \\
\hline After 24 hours & $125.8(33.3)$ & $101.0(19.9)$ & $<0.05$ \\
\hline \multicolumn{4}{|l|}{$\mathrm{TAC}(\mu \mathrm{mol} \mathrm{HClO} / \mathrm{ml})$} \\
\hline At study entry & $738.7(246.8)$ & 996.5 (104.0) & $<0.05$ \\
\hline After 24 hours & $881.0(143.4)$ & $1058.2(102.7)$ & $<0.05$ \\
\hline \multicolumn{4}{|l|}{$\mathrm{SH}$ groups ( $\mu \mathrm{mol} / \mathrm{I})$} \\
\hline At study entry & $735.8(471.3)$ & 1249.0 (191.3) & $<0.05$ \\
\hline After 24 hours & $1074.5(77.3)$ & 1360.8 (327.4) & $<0.05$ \\
\hline $\begin{array}{l}\text { Unless otherwise indicate } \\
\text { Btot, plasma total bilirubi } \\
\text { hydroperoxide concentra }\end{array}$ & $\begin{array}{l}\text { mean (SD). } \\
\mathrm{n} ; \mathrm{TAC} \text {, total antioxide }\end{array}$ & $\begin{array}{l}\text { pacity of the plasma; } \mathrm{TH}, \mathrm{F} \\
\text { nbranes. }\end{array}$ & plasma tota \\
\hline
\end{tabular}

hydroperoxides are intermediate oxidative products of lipids, peptides, and amino acids. Measurement was with a d-ROMs kit (Diacron, Grosseto, Italy) as described by Buonocore et al. ${ }^{15}$ This method makes it possible to estimate the total amount of hydroperoxide present in a $10 \mu \mathrm{l}$ blood sample using a spectrophotometric procedure. Hydroperoxide groups are attacked by the iron, decompartmentalised from transport protein in $1 \mathrm{ml}$ acetate buffer at $\mathrm{pH} 4.8$, to catalyse reactive oxygen metabolite formation by Fenton's reaction. The peroxy and alkoxy radicals produced, the quantities of which are directly proportional to peroxides present in the plasma, are trapped chemically with $10 \mu \mathrm{l}$ of a chromogen $(N, N$-diethyl- $p$ phenyldiamine) in an electron transfer process, leading to the formation of the radical cation of this chromogen. The purple colour resulting from this reaction over time was monitored in a UV-VIS spectrophotometer (Perkin Elmer $\lambda$ 16, Norwalk, Connecticut, USA) at $505 \mathrm{~nm}$. The results were expressed in conventional units (Carr units); I Carr unit is equal to a concentration of $0.8 \mathrm{mg} / \mathrm{l}$.

TAC was measured by an OXY-Adsorbent test (Diacron) as described by Trotti et al.$^{16}$ This method is based on the ability of a massive dose of $\mathrm{HClO}$ to oxidise the physiological antioxidant agents (uric acid, reduced glutathione, thiol groups, vitamins, glutathione peroxidase, superoxide dismutase, catalase, etc.). The efficacy of the antioxidant system can be monitored indirectly by measuring the excess of $\mathrm{HClO}$ in the serum. As $\mathrm{HClO}$ reacts with a correctly buffered chromogenic substrate ( $N, N$-diethyl-p-phenyldiamine), a coloured complex develops which can be measured photometrically, giving a maximum peak of absorbance at 505 or $546 \mathrm{~nm}$. The concentration of the coloured complex is directly proportional to the concentration of $\mathrm{HClO}$ and indirectly to the antioxidant capacity. A $10 \mu \mathrm{l}$ blood sample, previously diluted $1: 100$ with distilled water, is added and mixed with $1 \mathrm{ml}$ oxidant solution and $10 \mu \mathrm{l}$ of the chromogen. The purple colour resulting from this reaction over time is then monitored in a UV-VIS spectrophotometer at 505 or $546 \mathrm{~nm}$. For each series of assays, a standard with an assigned value, previously diluted
1:100 with distilled water as for the samples, and a blank reagent, obtained by replacing serum with distilled water, were included. The absorbances were measured immediately. The absorbance of the reagent blank was subtracted from those of the standard and the samples. The antioxidant capacity, expressed as $\mu \mathrm{mol} \mathrm{HClO} / \mathrm{ml}$ serum, was calculated using the following formula:

$$
\left(\mathrm{Abs}_{\text {Blank }}-\mathrm{Abs}_{\text {Sample }}\right) /\left(\mathrm{Abs}_{\text {Blank }}-\mathrm{Abs}_{\text {Standard }}\right) \times[\text { standards }]
$$

where Abs is absorbance and [standards] is the standard concentration.

Protein SH groups were measured with the SHp Test (Diacron) using the spectrophotometric method of Ellman. ${ }^{17}$ This method is based on the ability of protein SH groups to bind to a chromogen (5,5'-dithiobis-(2-nitrobenzoic acid)). A $1 \mathrm{ml}$ sample is mixed with $20 \mu \mathrm{l}$ chromogen. The resulting yellow colour is then monitored in a UV-VIS spectrophotometer at $405 \mathrm{~nm}$. For each series of assays, a standard solution of 496 $\mu \mathrm{mol} / \mathrm{l} \mathrm{SH}$ groups was prepared. The concentration of $\mathrm{SH}$ groups, expressed as $\mu \mathrm{mol} / \mathrm{l}$, was calculated from the following formula:

$$
\begin{aligned}
& \mathrm{Abs}_{\text {Sample }}-\left(\mathrm{Abs}_{\text {Sample blank }}+\mathrm{Abs}_{\text {Reagent blank }}\right) /\left(\mathrm{Abs}_{\text {Standard blank }}+\right. \\
& \left.\mathrm{Abs}_{\text {Reagent blank }}\right) \times 496
\end{aligned}
$$

where Abs is absorbance and 496 is the standard concentration of $\mathrm{SH}$ groups.

\section{Statistical analysis}

We had calculated that a sample size of at least 12 infants in each group was required to detect a significant correlation between a change of $30 \%$ in $\mathrm{TH}$ and a change of $50 \mu \mathrm{mol} / \mathrm{l}$ in Btot, with $80 \%$ power at the 0.05 level.

The data were expressed as mean (SD) and analysed for significant differences by analysis of variance for continuous variables and the $\chi^{2}$ test for rates and proportions. Simple 

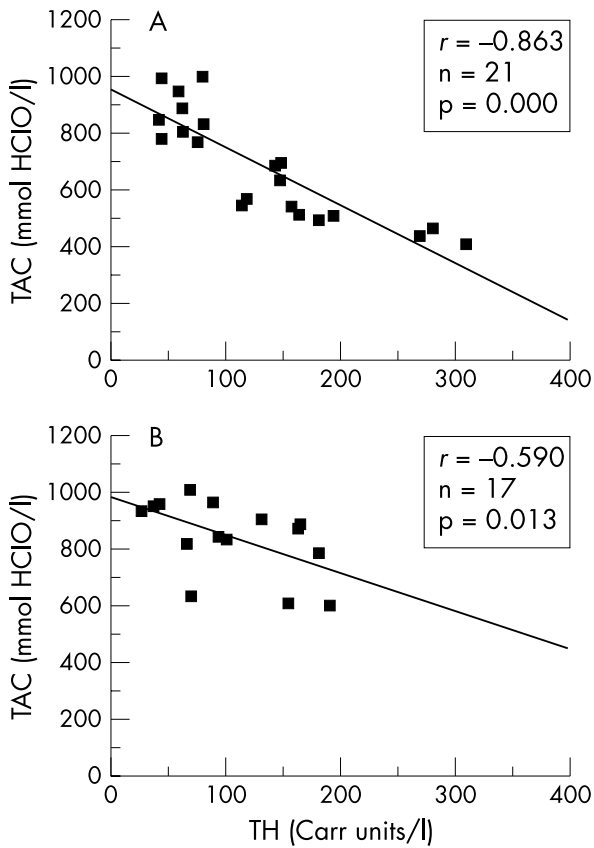

Figure 1 Correlation between plasma total hydroperoxide concentration (TH) and total antioxidant capacity of the plasma (TAC) at study entry (A) and after 24 hours (B).

regression analysis was used to assess the correlation between bilirubin, TH, TAC, and protein SH groups.

\section{RESULTS}

Infants with ( $\mathrm{n}=22)$ and without $(\mathrm{n}=9)$ hyperbilirubinaemia exhibited similar characteristics with regard to male/ female ratio, gestational age, birth weight, type of delivery, Apgar score at five minutes, antenatal steroid treatment, maternal disorders, and age at blood sampling (table 1). All infants received human milk (from his/her mother or from a donor) from the first day of life, and 12/22 (55\%) and 4/9 $(44 \%)$ were receiving glucose/saline intravenous infusion at the time of blood sampling.

All the neonates with hyperbilirubinaemia were admitted with the diagnosis of prematurity, but eight patients experienced symptomatic hypoglycaemia during the first 3 days of life, and five developed moderate feeding intolerance. Fourteen patients were treated with conventional phototherapy during the study period.

Owing to the small size of the blood samples in some patients, it was not possible to determine $\mathrm{TH}$ at study entry $(\mathrm{n}=1)$, protein $\mathrm{SH}$ groups at study entry $(\mathrm{n}=2)$, and TAC at study entry $(n=1)$ and after 24 hours $(n=5)$.

Btot was higher $(\mathrm{p}<0.05)$ at study entry (219 (25.9) $\mu \mathrm{mol} / \mathrm{l})$ than after 24 hours $(188$ (27.6) $\mu \mathrm{mol} / \mathrm{l})$, whereas albumin (28.5 (2.4) v $29.2(2.7) \mathrm{g} / \mathrm{l})$, ferritin (162.5 (71) $v 172$ (45) $\mu \mathrm{g} / \mathrm{l})$, and iron (15.1 (11.5) $v 14.9$ (10.2) $\mu \mathrm{mol} / \mathrm{l})$ concentrations remained unchanged. TH decreased from 151.8 (39.7) to 125.8 (33.3) Carr units $/ 1$ ( $<<0.05)$. TAC rose from 738.7 (246.8) to 881.9 (143.4) $\mu \mathrm{mol} \mathrm{HClO} / \mathrm{ml}(\mathrm{p}<0.05)$, and protein SH groups increased from 735 (471.3) to 1074 (577.3) $\mu \mathrm{mol} / \mathrm{l}(\mathrm{p}<0.01)$ (table 1$)$.

Btot did not correlate with TH (at study entry: $r=0.009$, $\mathrm{p}=0.967$; after 24 hours: $r=0.284, \mathrm{p}=0.212$ ), TAC (at study entry: $r=-0.023, \mathrm{p}=0.929$; after 24 hours: $r=-0.165$, $\mathrm{p}=0.526$ ), or protein SH groups (at study entry: $r=-0.303$, $\mathrm{p}=0.194$; after 24 hours: $r=0.138, \mathrm{p}=0.541$ ). A significant correlation was observed between TH and TAC (fig 1), TH and protein SH groups (fig 2), and TAC and protein SH groups (fig $3)$, both at study entry and after 24 hours.
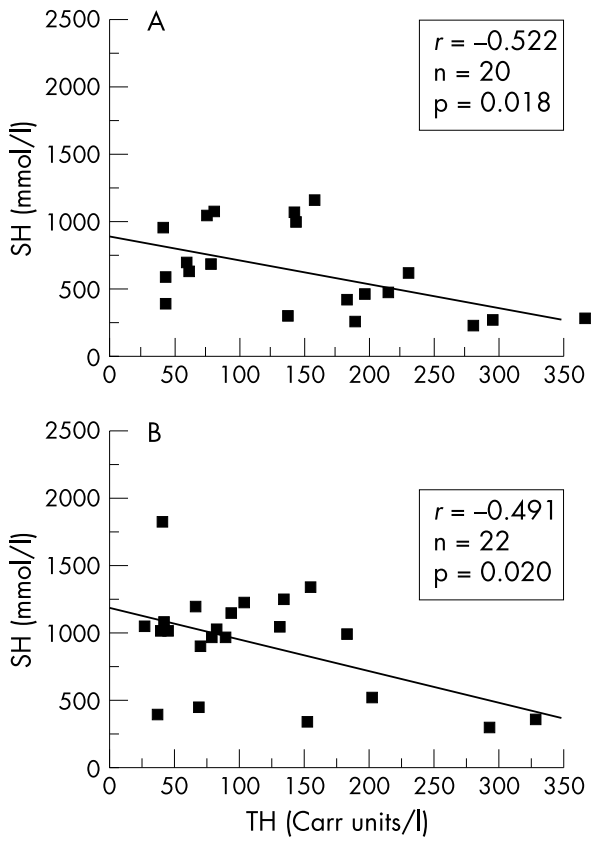

Figure 2 Correlation between plasma levels of protein $\mathrm{SH}$ groups (SH) and total hydroperoxides (TH) at study entry ( $\mathrm{A})$ and after 24 hours (B).
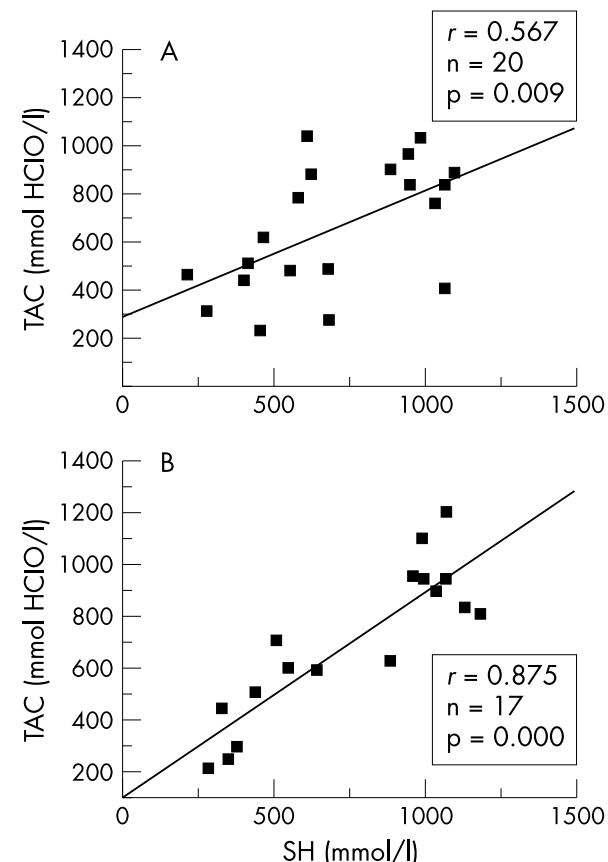

Figure 3 Correlation between plasma levels of protein $\mathrm{SH}$ groups (SH) and total antioxidant capacity of the plasma (TAC) at study entry (A) and after 24 hours (B).

The infants without hyperbilirubinaemia were admitted because of their prematurity, and two had hypoglycaemia. Their Btot values were 94.8 (8.6) $\mu \mathrm{mol} / \mathrm{l}$ and 105 (17.7) $\mu \mathrm{mol} / \mathrm{l}$ after 24 hours, with plasma albumin concentrations of 27.6 (3.4) $v 29.2(4.8) \mathrm{g} / \mathrm{l}$. Ferritin (154.5 (65) $v 149$ (52) $\mu \mathrm{g} / \mathrm{l}$ ) and iron $(14.9$ (10.6) $v 16.2$ (12.4) $\mu \mathrm{mol} / \mathrm{l})$ concentrations were similar at study entry and after 24 hours and also similar to the concentrations in infants with visible jaundice.

We did not find a significant difference between initial and later (after 24 hours) values for TH (101.3 (27.8) and 101.0 (19.9) Carr units/1), TAC (996.5 (104.0) and 1058.2 (102.7) 
$\mu \mathrm{mol} \mathrm{HClO} / \mathrm{ml}$ ), and protein SH groups (1249.0 (191.3) and $1360.8(327.4) \mu \mathrm{mol} / \mathrm{l})$. These values were significantly different from those of the jaundiced infants (table 1).

\section{DISCUSSION}

Our data show a decrease in plasma bilirubin concomitant with an increase in plasma antioxidant capacity and decrease in oxidative stress in preterm infants. These results seem to disagree with previous studies using in vitro ${ }^{5-8}$ and animal ${ }^{9}$ models, both of which showed antioxidant properties of bilirubin. However, the latter studies, although accurate, could not exactly replicate what occurs in human beings, especially preterm infants. Furthermore, bilirubin has not always been found to be effective as an antioxidant agent: Mireles et al ${ }^{8}$ showed in vitro that, after oxidative stress, a bilirubin concentration $>30 \mathrm{mg} / \mathrm{dl}$ is associated with an increase in protein oxidation; moreover, the infusion of $15 \mathrm{mg} / \mathrm{kg}$ bilirubin in an animal model was not effective in preventing the oxidative stress and pulmonary hypertension induced by group B streptococcus. ${ }^{18}$

Our results confirm the findings of Yigit et al ${ }^{10}$ who did not find a correlation between serum malondialdehyde and bilirubin concentrations in preterm infants with nonhaemolytic hyperbilirubinaemia, and Gopinathan et al, ${ }^{11}$ who did not observe a correlation between serum bilirubin and total plasma antioxidant capacity in preterm infants. On the other hand, Belanger et $a l^{12}$ found a reduction in antioxidant capacity of plasma after exchange transfusion and the subsequent decrease in plasma bilirubin. As suggested by the authors, this result could be explained by factors other than bilirubin decrease, such as the oxidative stress induced by a large amount $(170 \mathrm{ml} / \mathrm{kg})$ of transfused blood and the consequent overload of iron caused by the transfusion. ${ }^{19}$ Also Hammerman et $a l^{13}$ found that serum bilirubin and plasma antioxidant capacity are correlated, but the small size of their study population makes their results inconclusive.

To explain our results, we considered that the antioxidant action of bilirubin had been definitively shown, ${ }^{2-7}$ and that, as suggested by the lack of correlation between Btot and the remaining variables studied in our patients, factors other than bilirubin must have caused the increase in plasma antioxidant capacity and the decrease in oxidative stress in association with the decrease in Btot. On the other hand, the higher TH and the lower TAC and SH group levels measured in jaundiced infants compared with infants without jaundice seems to suggest that the former may have some condition that predisposes them to an increase in oxidative stress when plasma bilirubin increases.

Haem oxygenase has been reported to have a role as a prooxidant agent. ${ }^{20}$ It is the enzyme responsible for physiological haem degradation; it catalyses the degradation of haem to equimolar amounts of carbon monoxide, biliverdin, and iron. ${ }^{21}$ Three isoforms have been isolated, the inducible haem oxygenase (HO-1), the constitutive haem oxygenase (HO-2), and the more recently discovered and less active haem oxygenase (HO-3). ${ }^{22} \mathrm{HO}-\mathrm{l}$ is a known stress protein, the transcription of which can be induced by a whole array of stressors, including endotoxin, transition metal ions, haem, haemin, haemoglobin, and other haem proteins.$^{20}$ Indeed, it has been suggested that HO-1 induction may represent a generalised response to oxidative stress $\mathrm{s}^{22-24}$ and that it may confer cellular protection against oxidant stress. ${ }^{2125-27}$ The protection mechanism is unclear, although removal of pro-oxidant haem, synthesis of antioxidant bilirubin, and induction of ferritin synthesis, which sequesters redox active iron, may be involved. $^{28}$ However, other studies ${ }^{19} 29$ suggest that HO-1 induction may not always be beneficial and that the release of redox active iron from haem may induce an increase in oxidative stress. Moreover, studies in vitro ${ }^{30}{ }^{31}$ have suggested that the possible protective antioxidant action of haem oxygenase may occur within a narrow range, so in cases in which it is overexpressed, iron released may prevent any cytoprotective effect against oxidative stress. ${ }^{32}$

Therefore we speculate that our results could be explained by the pro-oxidant activity of an overexpressed haem oxygenase, which, on degrading haem, produces equimolar amounts of bilirubin and low molecular mass iron. The latter may be the actual cause of oxidative stress in our patients because of the lack of adequate synthesis of ferritin, ${ }^{27}$ which effectively removes iron.

In conclusion, we found that, in our preterm infants, the decrease in plasma bilirubin was concomitant with an increase in the antioxidant capacity of the plasma and a decrease in oxidative stress. We speculate that this is the result of the pro-oxidant effect of haem oxygenase mediated by iron release, which counteracts the antioxidant properties of bilirubin. Further studies are required to confirm our results and speculations.

\section{Authors' affiliations}

C Dani, E Martelli, G Bertini, M Pezzati, L Filippi, F F Rubaltelli, Division of Neonatology, Careggi University Hospital of Florence, Florence, Italy

M Rossetti, G Rizzuti, Central Laboratory of Chemical-Clinical Analysis, Careggi University Hospital of Florence

\section{REFERENCES}

1 Thibeault DW. The precarious antioxidant defenses of the preterm infant. Am J Perinatol 2000;17:167-81

2 Miller NJ, Rice-Evans C, Davies M, et al. A novel method for measuring antioxidant capacity and its application to monitoring the antioxidant status in premature neonates. Clin Sci 1993:84:407-12.

3 Stocker R, Yamamoto Y, McDonagh AF, et al. Bilirubin is an antioxidant of possible physiological importance. Science 1987;235:1043-6.

4 Stocker R, Ames BN. Potential role of conjugated bilirubin and copper in the metabolism of lipid peroxides. Proc Natl Acad Sci USA 1987;84:8130-4.

5 Wu TW, Wu J, Li RK, et al. Albumin-bound bilirubin protects human ventricular myocites against oxyradical damage. Biochem Cell Biol 1991;69:683-8.

6 Stocker R, Glazer AN, Ames BN. Antioxidant activity of albumin-bound bilirubin. Proc Natl Acad Sci USA 1987;84:5918-22.

7 Stocker R, Yamamoto Y, McDonagh AF, et al. Bilirubin is an antioxidant of possible physiological importance. Science 1987:235:1043-6.

8 Mireles LC, Lum MA, Dennery PA. Antioxidant and cytotoxic effects of bilirubin on neonatal erythrocytes. Pediatr Res 1999;45:355-62.

9 Dennery PA, McDonagh AF, Spitz DR, et al. Hyperbilirubinemia results in reduced oxidative injury in neonatal Gunn rat exposed in hyperoxia. Free Radic Biol Med 1995; 19:395-404.

10 Yigit S, Yurdakok M, Kilinc K, et al. Serum malondialdehyde concentrations in babies with hyperbilirubinemia. Arch Dis Child Fetal Neonatal Ed 1999;80:F235-7.

11 Gopinathan V, Miller NJ, Milner AD, et al. Bilirubin and ascorbate antioxidant activity in neonatal plasma. FEBS Lett 1994;349:197-200.

12 Bellanger S, Lavole JC, Chessex P. Influence of bilirubin on the antioxidant capacity of plasma in newborn infants. Biol Neonate 1997;71:233-8.

13 Hammerman C, Goldstein R, Kaplan M, et al. Bilirubin in the premature: toxic waste or natural defense? Clin Chem 1998;44:2551-3.

14 Rubaltelli FF, Glenn RG, Loskamp N, et al. Transcutaneous bilirubin measurement: a multicenter evaluation of a new device. Pediatrics 2001;107:1264-71.

15 Buonocore G, Perrone S, Longini M, et al. Total hydroperoxide and advanced oxidation protein products in preterm hypoxic babies. Pediatr Res 2000;47:221-4.

16 Trotti R, Carratelli $M$, Barbieri $M$, et al. Oxidative stress and a trombophilic condition in alcoholics without severe liver disease. Hematologica 2001;86:85-91.

17 Ellman GL. Tissue sulfhydryl groups. Arch Biochem Biophys 1959;82:70-7.

18 Pauly TH, Smith M, Gillespie M. Bilirubin as an antioxidant: effect on non group $B$ streptococci-induced pulmonary hypertension in infant piglets. Biol Neonate 1991;60:320-6.

19 Gutteridge JMC. Fate of oxygen free radicals in extracellular fluids. Biochem Soc Trans 1982;10:72-3.

20 Lamb NJ, Quinlan GJ, Mumby S, et al. Haem oxygenase shows pro-oxidant activity in microsomal and cellular systems: implication for the release of low-molecolar-mass iron. J Biochem 1999;344:153-8.

21 Kimberly K, Bonkovsky E, Bonkovsky HL. Heme oxygenase: recent advances in understating its regulation and role. Proc Assoc Am Physicians 1999;111:438-47.

22 Keyse SM, Applegate LA, Tromvoukis Y, et al. Oxidant stress leads to transcriptional activation of the human heme oxygenase gene in cultured skin fibroblast. Mol Cell Biol 1990;10:4967-9. 
23 Vile GF, Basu-Modak S, Waltner C, et al. Heme oxygenase 1 mediates an adaptive response to oxidative stress in human skin fibroblasts. Proc Natl Acad Sci USA 1994:91:2607-10.

24 Lautier D, Luscher P, Tyrrell RM. Endogenous glutathione levels, modulate both constitutive and UVA radiation/hydrogen peroxide inducible expression of the human heme oxygenase gene.

Carcinogenesis 1992;13:227-32.

25 Dennery PA, Wong HE, Sridhar KJ, et al. Differences in basal and hyperoxia-associated $\mathrm{HO}$ expression in oxidant-resistant hamster fibroblasts. Am J Physiol 1996;271:L672-9.

26 Lee PJ, Alam J, Sylvester N, et al. Regulation of heme oxygenase-1 expression in vivo and in vitro in hyperoxic lung injury. Am J Respir Cell Mol Biol 1996; 14:556-68
27 Applegate LA, luscher P, Turrell RM. Induction of heme oxygenase: a general response to oxidant stress in cultured mammalian cells. Cancer Res 1991:51:974-8.

28 Balla G, Jacob HS, Balla J, et al. Ferritin: a cytoprotective antioxidant stratagem of endothelium. J Biol Chem 1992;267:18148-53.

29 Dennery PA, Spitz DR, Yang G, et al. Oxygen toxicity and iron accumulation in the lungs of mice lacking heme oxygenase-2. J Clin Invest 1998;101:1001-11.

30 Dennery PA, Sridhar KJ, Lee CS, et al. Heme oxygenase-mediated resistance to oxygen toxicity in hamster fibroblasts. J Biol Chem 1997:272:14937-42.

31 Suttner DM, Sridhar K, Le CS, et al. Protective effects of transient HO-1 overexpression on susceptibility to oxygen toxicity. Am J Physiol $1999 \cdot 276:[443-51$

32 Dennery PA. Regulation and role of heme oxygenase in oxidative injury. Curr Top Cell Regul 2000;36:181-99.

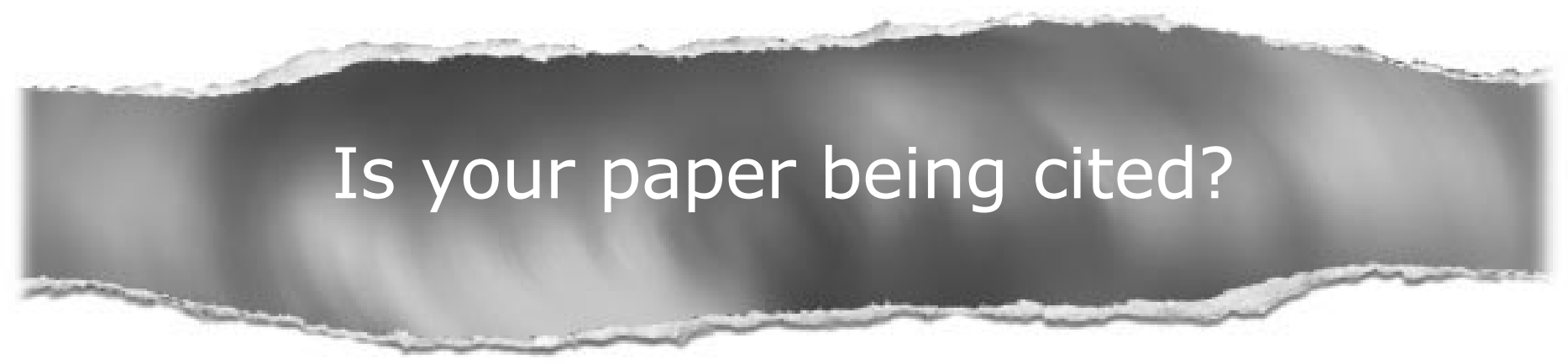

\section{CiteTrack service}

CiteTrack will alert you by email whenever new content in Archives of Disease in Childhood or a participating journal is published that matches criteria you want to track

Topics: Tell CiteTrack which words or subjects to watch for in new content Authors: Be alerted whenever key authors you are following publish a new paper Articles: Know whenever a paper of interest to you is referenced by another paper

\section{www.archdischild.com}

